\title{
GUERRA CIVIL
}

\section{FUNDAMENTO DO DIREITO DE REVOLUÇÃO}

Ninguem poderá contestar a legitimidade do direito de revolução em face da Philosophia. Alguns o fundam na inalienabilidade da soberania, na delegação de seu exercicio é na sua revogabilidade. Outros, no pacto commissario "causa data, causa non secuta" Numerosos, finalmente, sustentam o direito de revolução, baseando-o no principio de legitima defesa.

Perguntam os adeptos desta escola: si o despota affronta minha consciencia, si queima Roma, si sacrifica minha familia, si arruina minha patria, sii depreda o thesouro, não tenho o direito e o dever de defender-me?

\section{OS PAPAS, OS DOUTOS, AS LEIS..}

Os papas, como Bonfacio VIII (1294) e Gregorio VII, doutores da autoridade de Lainez e Marianna, foram adeptos do direito de revolução, acceito e defendidlo modernamente por escriptores da estatura de Vareilles Sommières e Duguit.

Desde Suarez (De Bello, disp. 13 cap. 8. ${ }^{\circ}$ ), Sto. Thomaz (Reg. Princ. lib. I, cap. 6. ${ }^{\circ}$ ), o protestante Jurieu e as leis de Creta (Aristoteles, Polit. lib. 12, cap. 10. ${ }^{\circ}$, Platão, Rep. 1. 9. ${ }^{\circ}$ ) e da Polonia, lembrada por Montesquieu, até aos tempos mais recentes, numerosos são os doutos, papas, philosophos e jurisconsultos que defendem o direito de revolução e numerosas as leis que o reconhecem. 


\section{O DIREITO DE REVOLUÇÃO}

0 direito de revolução, justificado pela religião, acceito pelos papas e philosophos, existe como uma consequencia logica do "regimen democratico" Proclamar.no escriptores e leis. Diz Cooley: "O direito de revolursão existe, póde dizer-se logo que o governo se tenha tornado tão oppressivo que as suas calamidades prepondierem de. cididamente sobre aquellas que forem capazes de acarretar com uma mutação, desde que o successo seja razoavelmente certo, e desde que taes instituiçõos satisfaçam a vontade do povo" (V. t. Woosley, Pol. Sc., I p. 402).

\section{BLACK}

O grande Black (Const. Law, p. 10), assim se exprime: "The right of revolution is the inherent right of a people to cast out their rulers, change their polity, or effect radical reforms intheir system of governement or institutions, by force or a general reprising, whue the legaland constitutional methods of making such changes have proved inadequate, or are so obstructed as to be unavailable" Expondo a materia deste paragrapho $8 .^{\circ}$, reconhece o direito de revolução como um direito natural, fundamental, de que o povo comtudo só se deve servir em casos excepcionaes.

\section{A DECLARAÇÃO DE VIRGINIA}

A declaração de Virginia (1776), proclamava o direito de revolução nos seguintes termos: "Quando um governo não é adequado ou é contrario a esses fins (o beneficio commum, a protecção e segurança do povo) a maioria da communhão tem o indubitavel, inalienavel e irrevogavel direito de o reformar, alterar ou abolir pela forma que julgue melhor para o bem geral" 


\section{A DECLARAÇÃO DE INDEPENDENCIA}

$\mathrm{O}$ acto de declaração de independencia dos Estados Unidlos diz emphaticamente: "Se um governo qualquer que seja a sua forma, chega a desconhecer este fim (garantir os direitos do homem, derivando seus poderes do consentimento dos subordinados), póde o povo legitimamente modifical-o ou supprimil-o, e instituir um governo novio, assentado sobre taes principios" Não é só na America do Norte que é reconhecido este direito. $\mathrm{Na}$ França a

\section{DECLARAÇÃO DE DIREITOS}

ensina que: "O fim de toda a associação politica é a conservação dos direitos naturaes e imprescriptiveis do homem. Estes direitos são a liberdade, a propriedade, a segurança e a resistencia á oppressão" (art. II).

\section{ARGENTINA}

Sobre a materia póde vêr-se com proveito González Calderón (Der. Const. p. 370, vol. $1 .^{\circ}$ ).

\section{O DIREITO DE POSSUIR E TRAZER ARMAS}

A emenda segunda da constituição americana declara que ".. sendo necessaria á segurança de um Estado livre uma milicia bem organizada não será jámais violado o direito que tem o povo de possuir e trazer armas"

E', como ensina "Cooley", um resultado do protesto contra a dimnastia derrocada da Inglaterra que pretendera desarmar o povo, do que resultou o "bill de direitos" (1668). 


\section{OBJECTIVO}

Esse direito de possuir e trazer armas, que é geral, tinha não só como objectivo servir de freio contra as usurpações e demasias do poder, como tambem excluir toda e qualquer idéa da necessidade de um exercito permanente pois " $O$ exercito permanente é instituição condemnada pelas tradições e pelos sentimentos do povo, como sendo perigoso á sua liberdade, ao passo que o preparo geral do povo no manejo das armas para a defesa das instituições é o que basta conservar" (Cooley).

$\mathrm{V}$ t. (Black p. 543 paragrapho 207).

\section{AS CONSTITUIÇÕES AMERICANAS}

Ensina "Stimson" (Federal and States constitutions) que as constituições de varios Estados declaram que " the people shall have the right tobear arms in defense of themselves and the State (Ala. I, 26; Ariz; Ark.; Col., II, 13; Mass.; Tex.; Wyom.; Ore.; Tenn.; etc.); and this is perhaps implied in three other States" Em outros, é declarado simplesmente que: " they have the right to bear arms"

Quanto ás milicias e á lei marcial reporto-me a Stimson, p. 244 paragrapho 290.

\section{A CONSTITUIÇÃO ARGENTINA}

$\mathrm{O}$ art. 21 da Constituição Argentina dispõe que: “ todo cidadấo argentino é obrigado a armar-se para defesa da patria e desta constituição"

J. V. Gonzalez (n. 203 paragrapho 309), trata da materia, aliás esgotada por Gonzalez Calderon. 


\section{DIREITOS NÃO ENUMERADOS}

Diz a Cont. Argentina: "Las declaraciones, derechos y garantias que enumera la constitución, no serán entendidos como negación de otros derechos y garantias no enumerados, pero que nascen del principio de la soberania del pueblo y de la forma republicana, de gobierno" (art. 33).

$\mathrm{Diz}$ a constituição brasileira: "A especificação das garantias e direitos expressos na constituição não exclue outras garantias e direitos não enumerados, mas resultantes da forma de governo que ella estabelece e dos principios que consigna" (art. 78). Vê-se pela simples confrontação dos textos a sua semelhança assombrosa, o que levou o insigne constitucionalista brasileiro Carlos Maximiliano a d'izer que o art. 78 da nossa constituição é o mesmo art. 33 da Argentina, $4 .^{\circ}$ da lei basica de Portugal e emenda 9. ${ }^{a}$ do estatuto americano.

Mas, quaes serão estes direitos não enumerados?

Diz González Calderon: "Hay muchhs derechhs que apesar de no estar enumerados en la constitución nascen del principio de la soberania del pueblo y que, como ya se ha esplicado, este se ha reservado, sin que on manera alguna puedan ser desconocidos.

Eł ejemplo más sobresaliente de estos derechos reservados por el pueblo de la Republica es el derecho de "resistencia a la opressión" o derecho de revolución"

(Der. Const. Arg., I. p. 369). Em nota (pag. 371) ajunta o grande constitucionalista argentino: "Entre los derechos no enumerados por la constitución y que están comprehendidos en la declaración general del art. 33, se halla el "derecho de tener y llevar armas" reconocido expressamente por algunas constituciónes, como la norte-americana (art. II de las enmiendas. "En donde existe un gobierno basado sobre el principio de la soberania del pueblo, y nadie ejerce poder sino por delegación del pueblo, es necessario que la fuerza que 
secunda la acción del gobierno sea del pueblo, y este animada de los sentimientos de este. Por consiguiente, en un pais que quiera tener constituciónes libres, "la constitución debe consagrar como uno de los derechos absolutos de los ciudadanos, que la ley no puede alterar, el de tener y llevar armas El pueblo que no está armado, podrá denominarse soberano, pero lo será solo nominalmente, no en realidad" "Florentino González" Lecc. de Derecho Const. (1889), cap. VI. - Los principios en que este derecho se funda son tan obvios que estará demás explicarlo extensamente" Os direitos não enumerados na nossa constituição são pois o de "resistencia á oppressão" e o de "possuir e trazer armas"

E si não fossem estes, quaes seriam elles?

\section{AS NOSSAS LEIS}

O direito de revolução é pois reconhecidio pela nossa constituição. Póde tambem deduzir-se do nosso Codigo Penal (arts. 32-34). Quem poderá negar lendo os arts. 32 e paragrapho e 35 paragrapho $2 .^{\circ}$, que o nosso Codigo não recuou no reconhecimento do direito de revoluçãa como consequencia da legitima defesa?

\section{A REVOLUÇÃO EM FACE DO DIREITO INTERNO}

A revolução prolongando-se transforma-se em guerra civil, e esta tem numerosas consequencias de ordem interna com projecções internacionaes. Internamente o governo denominado legitimo dirá que os revolucionarios são rebeldes, mas internacionalmente podem elles ser considerados perfeitamente belligerantes legitimos. A lucta, p. ex., entre um Estado federado e a união é uma verdadeira guerra, segundo ensina Oppenheim (II p. 75). 0 governo com 
suas autoridades constituidas chamará os revolucionarios de rebeldes e bandidos, estes declararão o governo fóra da lei, por traições e brutalidades.

São questões de direito interno.

\section{O -DIREITO INTERNACIONAL}

Com a situação interna dos Estados nada tem que ver o Direito Internacional e podemos dizer que: "El D. Internacional actual ha hecho, pues, un progreso al manifestar-se dispuesto a conceder la condición de beligerantes á los partidos revolucionarios ó a cuerpos francos siempre que esten organizados militarmente y que respeten las leyes de la guerra y combatan de buena fé por un principio politico" (Cruchaga).

Nenhum Estado póde ter immixtão nos negocios dos outros.

Cada povo tem o direito de ter o governo que quizer e mudal-o á sua vontade.

\section{A'S GUERRAS CIVIS - APPLICAM-SE AS LEIS DA GUERRA}

Halleck (Elements, p. 152), ensina que ás guerras civis applicam-se as leis da guerra. Diz Cruchaga! "Los dos bandos en que se divide el pais tienem estricta obligación de ajustar-se em sus procedimientos á la más severa observancia de ciertas reglas establecidas por la costumbre y exigidas por el derecho. Deberán hacer la guerra de conformidad con los principios que presiden la lucha internacional. En consecuencia, las leyes de la ocupación militar, las que se refieren al empleo de armas y projectiles, las relativas a los prisioneros, ambulancias, etc., doberán ser estrictamente observadas por los contendientes" 
Essa estricta observancia das leis da guerra não-implica de nenhum modo o reconhecimento da belligerancia, como ensina Halleck.

\section{RECONHECIMENTO DA BELLIGERANCIA}

Os paizes extrangeiros reconhecem em alguns casos a guerra civil como uma verdadeira guerra, produzindlo todos os effeitos juridicos da guerra internacional, o que é o reconhecimento da belligerancia.

\section{CONDIÇÕES}

Cruchaga ensina que são condições para o reconhecimento da belligerancia: 1. - Correcta organização da administração publica na secção territorial do Estado em que é exercida de facto a soberania; $20^{\circ}$ - o éxercito obedecer ás autoridades e observar as leis da guerra; proclamação de um principio de direito publico como justificativa da lucta.

Epitacio Pessoa por sua vez dispõe: "Para que os Estados extrangeiros possam reconhecer ao partido revoltado a qualidade de belligerante, é necessario:

a) que esse partido tenha conquistado uma exístencia territorial distincta, com a posse de uma parte dieterminada do territorio nacional;

b) que haja reunido os elementos de um governo regular e que esse exerça de facto, no territorio occupado, os direitos apparentes da soberania;

c) que a lucta seja mantida em seu nome por tropas organizadlas, sujeitas á disciplina militar e que observem os preceitos deste codigo relativos á guerra" (Art. 714). 


\section{EFFEITOS}

Como ensina Epitacio: "O reconhecimento da belligerancia pelos governos extrangeiros prođuzirá todos os effeitos ordinarios da neutralidade" (Art. 715).

\section{CONCLUSÃO}

São estas, resumidamente expostas, as considerações que desejavamos fazer sobre a guerra civil. Foi nosso principal intuito vulgarizar alguns conhecimentos de $\mathrm{Di}$ reito Internacional, tão descuradio éntre nós, conforme se demonstrou na revolução de 1924.

Oxalá, a lucta pelas armas, a revolução, até hoje, desgraçadamente, o unico meio comprovado de alcançar um povo a sua liberdade, nunca jámais empape die sangue o solo de nossa queridla Patria.

Mas, si algum dịa houver entre nós uma lucta fratricida, procedamos como homens civilisados e humanos e não como salteadores ferozes, como assassinos sanguinarios.

S. Paulo, 25 de Abril de 1927

BRAZ DE SOUSA ARRUDA 